\title{
A NOTE ON THE THEORY OF A DWARF RACE OF LOBSTERS ON THE NORFOLK COAST
}

\author{
By Michael Graham
}

Fisheries Laboratory, Lowestoft

(Text-fig. I)

At the Annual Conference of Sea Fisheries Committees held in 1947, some members expressed the view that the lobsters being fished at Sheringham belonged to a dwarf race, distinct from the lobsters found at other ports. Such a view, acceptable as it might be to those who have always thought of lobster populations as local, presented certain difficulties to those familiar with Meek's conception of lobsters migrating long distances. Meek (1925) refers to his theory, but has not described evidence to substantiate it.

In this situation, the theory of a dwarf race seemed worth inquiry, and, fortunately, data are available.

The Interdepartmental Committee on Crabs and Lobsters (see its Report on lobsters issued in 1936) instituted investigations of the sizes of the lobsters in various districts in $193^{8-39}$, noting separately the sizes of mature females. It was evident that these data would provide the crucial test of the theory of dwarfness, namely an estimate of the size at first maturity in various districts, including that of the supposed dwarfs at Sheringham. English data obtained from these investigations have now been examined.

The data were collected at twelve stations on the English coast. At each station, one fisherman was selected to supply information of the length, sex, and condition of all lobsters in his catches. A copy of the instructions issued to the fishermen, and of the details they were asked to supply, is given in the Appendix (p. 487). (Measuring boards were supplied by the Fisheries Department.) At the same time, Collectors of Fishery Statistics were obtaining statistics of the total landings of shellfish, number of boats used, etc., at the same stations. All English records were returned to the Fisheries Department in London.

These records have now been summarized, port by port, for the period of the investigations-early summer 1938 to autumn I939- to give distribution by length and sex of marketable and non-marketable lobsters.

Table I shows that, undoubtedly, smaller lobsters were being caught at Sheringham, where, for example, cocks and non-berried hens of less than 8 in. represent $30 \%$ of the catch, a higher figure than at any other port. This was doubtless the basis for the belief in a dwarf race of lobsters in this locality, and were this the only statistical guide available, the theory of a dwarf race would not be unacceptable. However, the size-distribution of the mature females 
Table I. Summary of Results of Lobster Measuring (Tests made DURing May 1938 to September 1939)

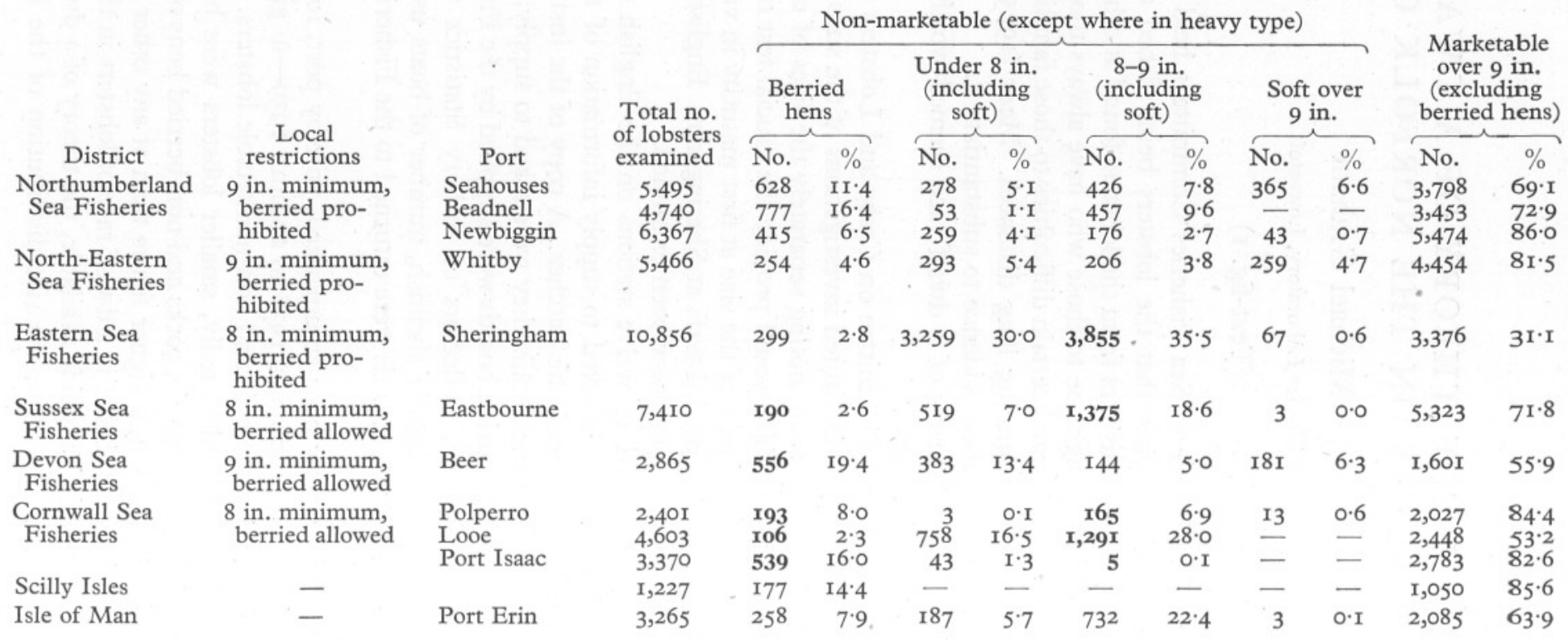


gives the correct solution on this point. In Table II and Fig. I, which include only mature female lobsters, the figures give the number of berried hens that were taken in each I in. group, and show which was the most popular lengthgroup at each port.

It will be observed, in Fig. I, that at Sheringham, as at all other stations, few berried hens are found of less than Io in. Furthermore, at six of the ports, including Sheringham, the IO-II in. group is the largest represented and it shows up conspicuously at still another. The berried hens at Sheringham, then, do not show any marked difference in size from those at other ports. Since these hens are of normal size, it is most unlikely that the lobsters caught off Norfolk belong to a dwarf race.

It may be noted in passing that the same observations make it also unlikely, though not impossible, that the small size is due to stunted growth through local conditions.

The smaller size at Sheringham is most simply expressed as consisting of a higher proportion of young lobsters. This is shown by the following figures, which give the percentage of berried hens in the total catch, extracted from Table I.

\begin{tabular}{lrlrlr}
\multicolumn{2}{c}{ North Sea } & & \multicolumn{2}{c}{ English Channel } & \multicolumn{2}{c}{ Irish Sea } \\
& & & $\%$ & & $\%$ \\
Sheringham & $2 \cdot 8$ & Eastbourne & $2 \cdot 6$ & Port Erin & $7 \cdot 9$ \\
Whitby & $4 \cdot 6$ & Beer & I9.4 & Port Isaac & I6.0 \\
Newbiggin & $6 \cdot 5$ & Looe & $2 \cdot 3$ & & \\
Beadnell & I6.4 & Polperro & $8 \cdot 0$ & & \\
Seahouses & II. 4 & Scilly Isles & I4.4 & &
\end{tabular}

It will be observed that only $2 \cdot 8 \%$ of the lobster population caught at Sheringham consisted of berried hens. There are some other interesting points about these figures. The ports are arranged geographically, and the percentage rises from south to north in the North Sea. In the Channel and Irish Sea, there are also some indications of an order in the figures, but with discrepancies, such as the surprising difference between Polperro and Looe, and the high figure at Beer.

From the nature of the data, it is doubtful if much weight can be given at present to these and other points of interest. Only local investigations, properly designed, could give satisfactory information. Points for such investigations are: the apparent absence of any small lobsters at the Scilly Isles; the high percentage of large lobsters shown at Polperro and Port Isaac, in spite of less protection than at some other ports; the high proportion of mature lobsters shown at Beer; and the apparent evidence of difference in the populations fished from the adjoining ports of Polperro and Looe.

The small proportion of fully grown lobsters at Sheringham might be susceptible to either of the following explanations: (i) the stocks at Sheringham may be more severely fished, or (ii) the other North Sea ports, being upstream, 
TABLE II. LeNGTH OF BerRIED LoBSters

(The Number Caught, and Percentage, is Shown for each i IN. Group)

Station
Seahouses
Beadnell
Newbiggin
Whitby

Sheringham

Eastbourne

Beer

Looe

Polperro

Scilly Isles

Port Isaac

Port Erin

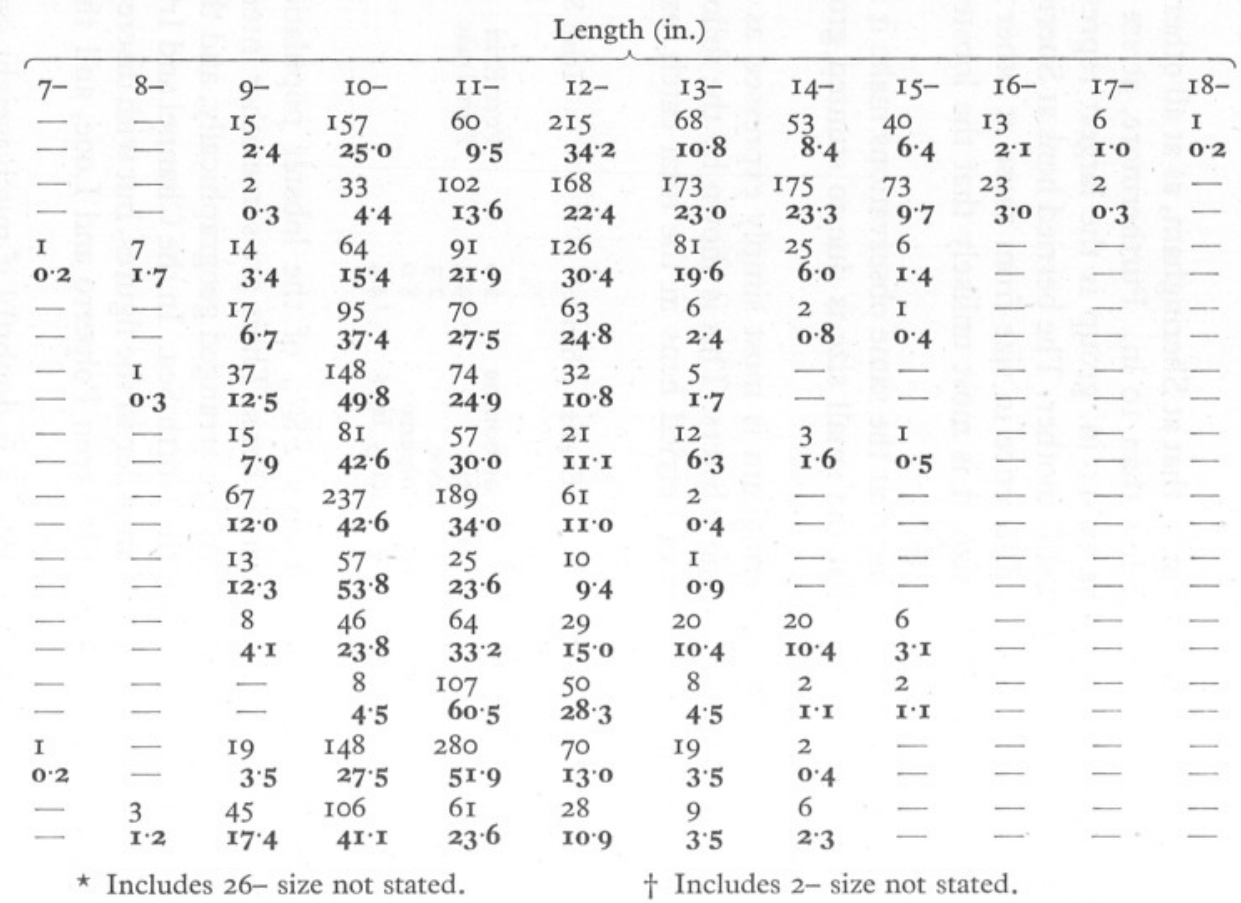

Total 628

I00.0 $777^{\star}$ 100.0 4I5 100.0 254
I00.0 $299 \dagger$ 100.0 I90 100.0 556 I00.0 I06 100. 0 I93 I00.0 I77 I00. 0 539 I00.O 258 I00.O 


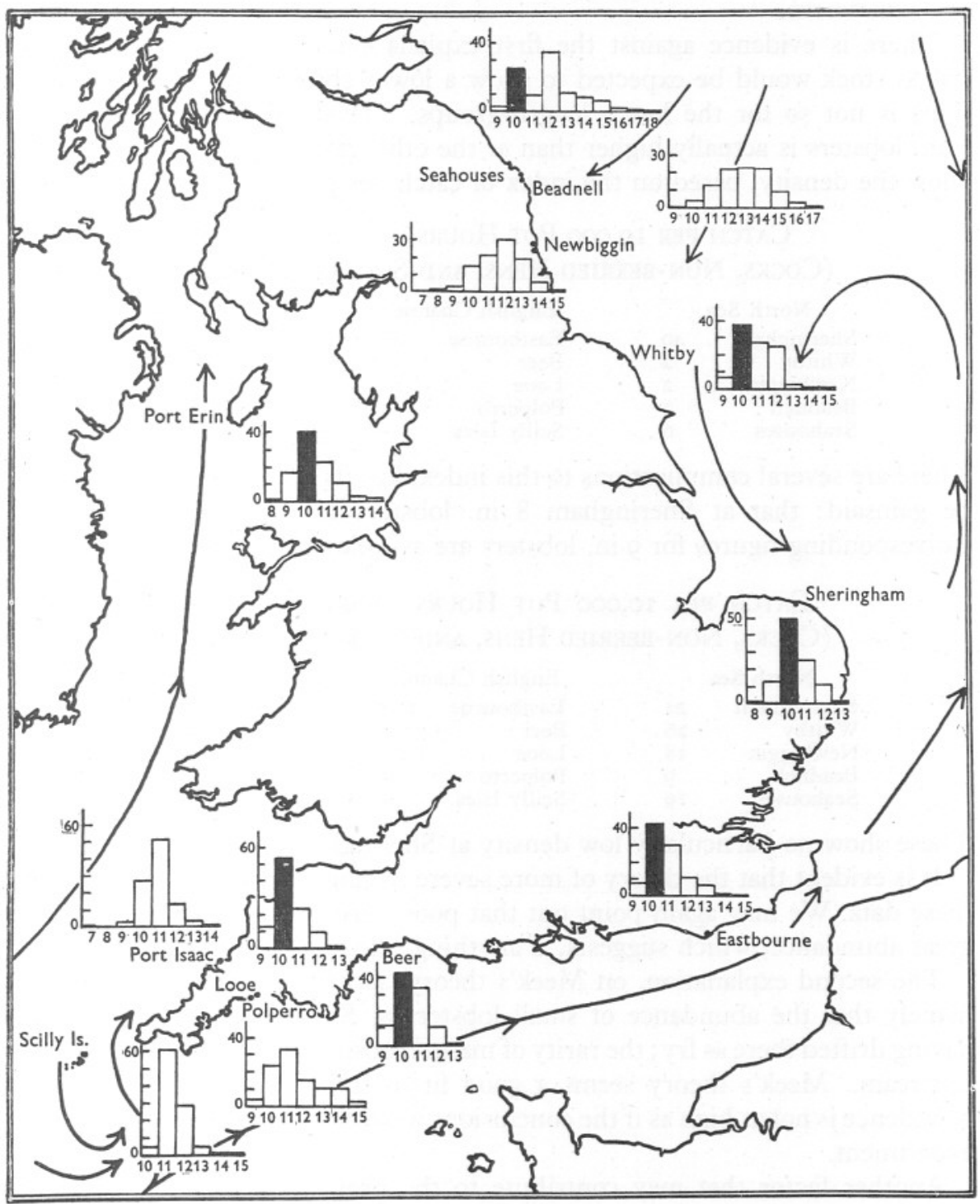

Fig. I. Lengths of mature female lobsters. The percentage at each length, by inches, reached or passed, of one fisherman's catch of berried hens in 1938 and 1939 is shown for each of twelve ports. At seven of the ports the length group of IO-II in. shows up conspicuously. The general current system is shown by arrows. 
might receive contranatant mature lobsters from the Sheringham district, which is downstream.

There is evidence against the first explanation, because a more severely fished stock would be expected to show a lower absolute density of lobsters. This is not so for the lower length-groups. The density at Sheringham of 8 in. lobsters is actually higher than at the other ports. The following figures show the density, based on the index of catch per pot hour.

\begin{tabular}{|c|c|c|c|c|c|}
\hline Sheringham & 40 & Eastbourne & 69 & Port Erin & \\
\hline Wr hith & 2 & & 6 & Port Isaac & 3 \\
\hline Newbiggin & 2 & Looe & I8 & & \\
\hline Beadnell & $\begin{array}{l}3 \\
6\end{array}$ & Polperro & 2 & & \\
\hline Seahouses & & Scilly Isles & & & \\
\hline
\end{tabular}

There are several complications to this index, but its main showing can hardly be gainsaid: that at Sheringham 8 in. lobsters are remarkably abundant. Corresponding figures for 9 in. lobsters are as follows:

CATCH PER IO,OOO POT HourS OF 9 IN. LOBSTERS (COCKS, NON-BERRIED HENS, AND SOFT OR UNDERSIZED)

\begin{tabular}{lrlrlr}
\multicolumn{2}{c}{ North Sea } & \multicolumn{2}{c}{ English Channel } & \multicolumn{2}{c}{ Irish Sea } \\
Sheringham & 2I & Eastbourne & I24 & Port Erin & 49 \\
Whitby & 26 & Beer & I5 & Port Isaac & 4 \\
Newbiggin & I8 & Looe & 20 & & \\
Beadnell & 9 & Polperro & 8 & & \\
Seahouses & I9 & Scilly Isles & 0 & &
\end{tabular}

These show no particularly low density at Sheringham.

It is evident that the theory of more severe fishing receives no support from these data. We may again point out that poor nurture would not explain this great abundance, which suggests, if anything, the opposite.

The second explanation, on Meek's theory, satisfies the data much better: namely that the abundance of small lobsters at Sheringham is due to their having drifted there as fry; the rarity of mature lobsters to their having migrated upstream. Meek's theory seems a good fit to these data, but the order of confidence is not as high as if the conclusions were based on a sufficient marking experiment.

Another factor that may contribute to the proportion of berried hens at various ports, and to the sizes of lobsters generally, is the fact that at the Northumberland ports the return of berried hens to the sea has been encouraged for longer than in other districts, perhaps causing more, and larger, hens to be found there.

I wish to acknowledge the assistance of Administrative and Statistical Officers of the Fisheries Department, in the preparation of this paper. 


\section{SUMMARY}

The evidence points strongly to the effect that Sheringham fishes the same race of lobsters as ports farther north. The most likely explanation of the smaller average size of the lobsters at Sheringham, which is shown to be due to abundance of small and rarity of large, is that it is in some way natural, and not due to fishing. A neat theory to fit the facts is Meek's, based on the position of Sheringham downstream in the main current system.

\section{REFERENCES}

InTERDEPARTMENTAL COMmittee ON CRABS AND LobSTers, I936. Report on Lobsters. H.M.S.O., London.

MEek, AlEXANDER, I925. Experimental legislation with reference to the crab and lobster fisheries of the East Coast of Britain. Fourn. Mar. Biol. Assoc., Vol. I3, pp. 755-68.

\section{APPENDIX}

The following instructions were issued on the front of the log book in which fisherman were to enter details of their catches:

I. Measure the whole catch.

2. Each lobster is to be measured from the tip of the beak to the end of the tail-plate.

3. All measurements are to be made in quarter inches and recorded by the last quarter inch reached or covered: thus, if the division at $10 \frac{1}{4}$ inches is covered but that at $10 \frac{1}{2}$ inches is not reached, the measurement is to be recorded as $10 \frac{1}{4}$.

4. Each length is to be recorded in a separate square.

5. The total number of each sort of lobster taken must be entered on the back of the form, including those rejected.

6. The forms, when completed, should be removed from the pads and handed to the Collector of Fishery Statistics on Monday of each week.

The details requested (Form no. B $438 /$ F.G.) were as follows:

On the front of the form were columns for entering lengths under the headings of:

Landed: Cocks; hens, not berried; hens, berried. Returned to the sea: berried hens; undersized or soft.

On the back of the form entries had to be made against:

Date... Ground... Depth... Number of pots lifted... Number of hours since pots were set. . . How many undersized returned to the sea?... How many soft returned to the sea?... How many berried hens returned to the sea?... How many berried hens landed?... How many non-berried hens landed?... How many cocks landed?... Other shellfish taken in pots and landed: crabs... crawfish.... 